\title{
DETECÇÃO DE CORPOS ESTRANHOS METÁLICOS POR MEIO DE FERROSCOPIA EM REBANHO BOVINO DE LEITE DE ALTA PRODUÇÃO
}

\author{
R.D. Ollhoff ${ }^{1^{*}}$; E.H. Birgel Junior ${ }^{2}$ \\ ${ }^{1}$ Universidade Católica do Paraná, BR 376 Rod. Curitiba-Joinville, km 14, CEP 83010-500, São José dos Pin- \\ hais, PR, Brasil. E-mail: daniel.ollhoff@pucpr.br
}

\section{RESUMO}

\begin{abstract}
Avaliou-se a presença de corpos estranhos metálicos (CEM) por meio de ferroscopia transabdominal em vacas de rebanho leiteiro de alta produção (>9.000 kg/lactação) mantidas em estabulação livre com fornecimento de ração total através de vagão alimentador. A ocorrência de CEM nos anos de 2005 e 2006 foi, respectivamente, igual a 83,67\% e 51,52\%, sendo que a amperagem máxima obtida durante a realização do exame foi igual a 9,36 \pm 7,54 $\mu \mathrm{A}$ em 49 vacas examinada no ano de 2005 e igual a 6,44 7,54 $\mu \mathrm{A}$ em 66 vacas examinada no ano de 2006. Verificou-se que em $44 \%$ (33/75) dos animais o CEM estava localizado no retículo (entre o quinto e sétimo espaço intercostal) e que em $56 \%$ (42/75) dos animais o corpo estranho estava localizado no rúmen. Após a exclusão de possíveis outras causas desta ocorrência, concluiu-se que no rebanho examinado a presença de CEM em mais da metade dos animais deveu-se, principalmente, a falhas na manutenção do vagão alimentador.
\end{abstract}

PALAVRAS-CHAVE: Bovinos, detector de metal, pré-estômagos.

\section{ABSTRACT}

DETECTION OF METALLIC FOREIGN BODIES THROUGH FERROSCOPY IN A HERD OF HIGH YIELD ASYMPTOMATIC DAIRY CATTLE. The presence of foreign metallic bodies through abdominal metal detector examination in high yielding dairy cattle $(>9,000 \mathrm{~kg}$ milk/lactation) under free-stall and TMR-feeding with a mixer wagon was evaluated. The occurrence of foreign metallic bodies in the years 2005 and 2006 was, respectively, $83.67 \%$ and $51.52 \%$, with a maximum of amperage measured during examination of $9.36 \pm 7.54 \mu \mathrm{A}$ in 49 cows in 2005 equal to $6.44 \pm$ $7.54 \mu \mathrm{A}$ in 66 cows in 2006 . A total of $44 \%$ (33/75) of the cows presented the foreign body in the reticulum (between the fifth and seventh intercostal space) and 56\% (42/75) in the rumen. The presence of foreign metallic bodies in most of the animals of the examined herd, after exclusion of other possible causes, was due to failures in the maintenance of the mixer wagon.

KEY WORDS: Cattle, metal detector, forestomachs.

A ingestão de corpos estranhos (CE) é frequentemente relatado nos bovinos em decorrência da primeira mastigação do alimento ser rudimentar, da sua deglutição ser rápida e da pequena sensibilidade gustativa observada nos animais dessa espécie (Rosenberger, 1970; CARMiCHAEL; EvANS, 1994; Frame, 2004; HARWOOD, 2004; MARTins et al., 2004). Particularmente, a ingestão de corpos estranhos metálicos ferrosos pontiagudos (pregos e arames) determina importantes prejuízos à bovinocultura de leite, causando retículo-peritonite traumáticas (Roth; King, 1991; WARD; Ducharme, 1994; FecteAu, 2005). Dependendo de sua natureza e localização, os corpos estranhos metálicos podem causar diferentes sintomatologias e migrarem para outros órgãos como o coração, o abomaso, o baço entre outros (Dietz et al., 1970; THORnTON, 1974; Nuss et al., 2004), podendo levar não raramente à morte dos animais (Roth; KING, 1991).

Após a ocorrência de caso de retículo-pericardite, em cuja necropsia recuperou-se quatro corpos metálicos pontiagudos medindo entre 3,0 e 4,5 $\mathrm{cm}$, pequenos pedaços de ferro, material de solda e diversas pedras, decidiu-se avaliar por meio de ferroscopia todas as vacas desse rebanho leiteiro. A fazenda localizava-se no Município de Fazenda

${ }^{2}$ Universidade de São Paulo, Faculdade de Zootecnia e Engenharia de Alimentos, Departamento de Zootecnia, Pirassununga, SP, Brasil.

*Programa de Pós-graduação em Ciência Animal (mestrado) - PUCPR. 
Rio Grande, região metropolitana de Curitiba, Paraná, produzia leite do tipo B e utilizava sistema de ordenha mecanizada no estilo carrossel. As vacas eram ordenhadas duas vezes ao dia com média de produção igual a de $33 \mathrm{~kg}$ de leite por dia/vaca. As vacas em lactação ficavam em regime intensivo em sistema de estabulação livre (free-stall). Não há compra ou introdução de animais de fora, sendo a reposição feita exclusivamente com novilhas nascidas no local. Para a alimentação dos animais adota-se o sistema de ração total (TMR - Total mixed ration), sendo o volumoso (silagem de milho produzida na própria localidade) misturado em vagão misturador com concentrado e sal mineral comercial e fornecido diretamente no cocho cimentado.

Os animais do rebanho foram avaliados duas vezes com intervalo de 15 meses, sendo realizados 49 exames no ano de 2005 e 66 no ano de 2009. Em 33 vacas foi possível a realização dos exames nos dois momentos. Para a realização do exame de ferroscopia foi utilizado aparelho para detecção de metal, modelo Hauptner. O sensor foi utilizado com sensibilidade 1 (a menor na escala disponível do aparelho que vai até 5) sendo passado em toda a área abdominal indo do quinto espaço intercostal até a altura do umbigo, aproximadamente, tanto do lado esquerdo quanto do direito. A amperagem das mensurações obtidas durante a realização do exame foram anotadas e registradas a localização na qual o corpo estranho metálico era detectado. Em todas as vacas positivas na ferroscopia foram realizados os testes para dor no retículo conforme preconizado por ROSENBERGER (1990), sendo que nenhuma apresentou reação de sensibilidade positiva.

O exame das 49 vacas em lactação no ano de 2005 revelou que $83,67 \%$ (41/49) dos animais apresentavam ferroscopia positiva, enquanto $51,52 \%(34 / 66)$ das 66 vacas examinadas no ano de 2006 apresentavam corpos estranhos metálicos. Seguindo as recomendações de ROSENBERGER (1990), considerou-se que os corpos estranhos estavam depositados dentro do retículo quando a sua detecção foi possível entre o quinto e o sétimo espaço intercostal. Os resultados obtidos evidenciaram que em 44,0\% (33/75) dos animais o CE metálico estava localizado no retículo (entre o quinto e sétimo espaço intercostal) e que em $56,0 \%(42 / 75)$ dos animais o corpo estranho estava localizado no rúmen. A ferroscopia não oferece informações sobre a forma do corpo estranho ingerido e, portanto, não permite diferenciar os corpos metálicos pontiagudos de corpos metálicos rombos ou limalha de ferro em pó. Esclarecimentos sobre a forma do CE metálico poderão ser obtidos com o auxílio da radiografia (FARROW, 1999; RAMPRABHU et al., 2003), mas dificilmente coma ultrasonografia (BRAUN, 2003).

Durante a realização da ferroscopia verificou-se significativa variação da amperagem obtida em todos os animais examinados. Em decorrência da atividade motora do compartimento retículoruminaléesperado uma diminuição do valor da leitura, pois as contrações do retículo e do rúmen determinam o afastamento entreessesórgãos e o transdutor do aparelho.Segundo FARROW (1999), o corpo estranho metálico no retículo somente poderia serconsideradolivre dentro daluz do órgão após dois ou mais exames radiográficos demonstrando a existência do mesmo em posições diferentes.

Verificou-se que a amperagem máxima obtida durante a realização do exame foi igual a 9,36 $\pm 7,54 \mu \mathrm{A}$ em 49 vacas examinadas no ano de 2005 e igual a 6,44 $\pm 7,54 \mu \mathrm{A}$, em 66 vacas examinada no ano de 2006 . Nas vacas que foram examinadas nos dois anos, verificouse que os valores de amperagem aumentaram em $30,3 \%(10 / 33)$ das vacas, permaneceram inalterados em 12,1\% (4/33) dos animais e diminuíram em 57,6\% (19/33) das vacas reexaminados, sendo que em 10 dessas 19 vacas os resultados da ferroscopia foram negativos no reexame. Em termos médios, os valores para a amperagem obtidos no primeiro exame das 33 vacas foi igual a 9,21 $\mu$ A e no segundo exame foi igual a 7,36 $\mu \mathrm{A}$. As explicações para essas variações nos resultados da ferroscopia encontrados nas vacas que foram reexaminadas poderiam ser a regurgitação do corpo estranho conforme descrito por WITTWER (1966) e CLARKE (1997) ou, mais provavelmente, decorrerem da corrosão do metal, que após ser cominuído em pequenos pedaços poderia ser transportado para outras porções do sistema digestivo ou dissolvido pelos processos fermentativos do rúmen. Desconhecem-se na literatura pesquisada acompanhamentos por longo período como o aqui relatado.

Investigando-se as possíveis causas da alta prevalência de corpos estranhos metálicos chegou-se como provável origem ao vagão misturador, pois o equipamento não possuía imãs na saída dos vagões e apresentava placas metálicas enferrujadas descolando-se do interior da lataria corroída pela ação dos sais minerais e dos ácidos da própria silagem (Fig. 1). Apesar do vagão misturador como origem de corpos estranhos metálicos ter sido relatadoanteriormentena Inglaterra por DANIEL; SMITH (2008), não foram encontradas referências sobre a sua ocorrência em rebanhos leiteiros brasileiros. A adequada manutenção dovagão misturador e a instalação de imãs potentes na saída dos vagões alimentadores são fundamentais para minimizar os riscos da ingestão de corpos estranhos metálicos. A diminuiçãona prevalência no ano de2006 deveu-se muito provavelmente à reforma do vagão misturador aliado a uma entrada considerável de animais jovens de reposição no rebanho, por menor tempo expostos ao alimento com presença de corpos estranhos. Não pode se descartar a possibilidade de nestes 15 meses entre um exame e outro não ter ocorrido a ingestão de outros $\mathrm{CE}$ como pregos ou arames, pois não foram instalados imãs no equipamento. 


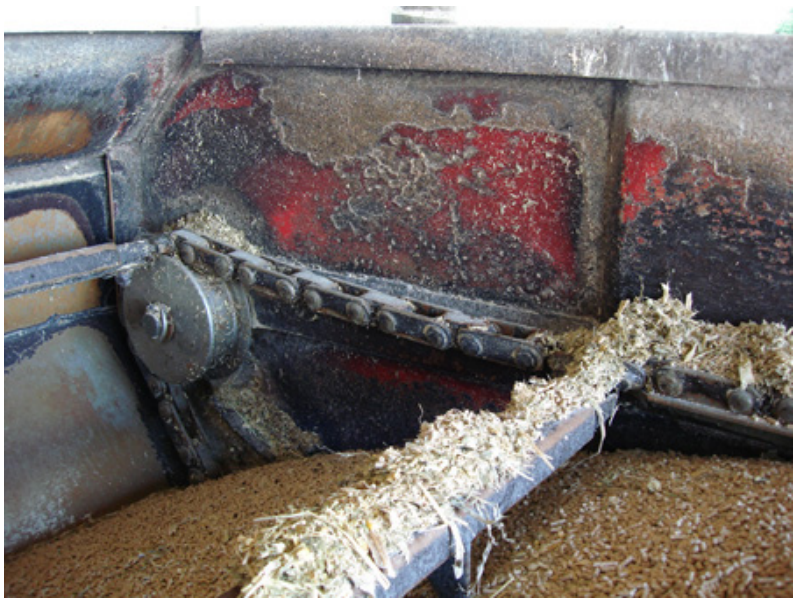

Fig. 1 - Vista interna da lataria do vagão misturador. Em primeiro plano o alimento, observam-se nas paredes laterais grandes placas de ferrugem, muitas descoladas, além de ferrugem e acúmulo de alimento nas engrenagens.

Este experimento foi realizado conforme os princípios éticos da experimentação animal estabelecidos pela Comissão de Ética no Uso de Animais da PUC-Paraná (nº 45/06/CEUA-PUCPR de 10/9/2006).

\section{REFERENNCIAS}

BRAUN, U. Ultrasonography in gastrointestinal disease in cattle. The Veterinary Journal, v.166, p.112-124, 2003.

CARMICHAEL, M.A.; EVANS, C.C. Stone swallowing. The Veterinary Record, v.135, p.608, 1994.

CLARKE, P.J. Unusual cause of rumen stasis in a cow. The Veterinary Record, v.140, p.636, 1997.

DANIEL, R.; SMITH, G. Suspected bovine reticuloperitonitis associated with the metal components of a mixer wagon. The Veterinary Record, v.162, p.563-564, 2008.

DIETZ, O.; LI, E.; NAGEL, E. Zur Klinik der komplizierenden Haubenfremdkörper beim Rind. Schweizer Archiv für Tierheilkunde, v.112, p.464-470, 1970.

FARROW, Ch. S. Reticular foreign bodies - Causative or coincidence? Veterinary Clinics of North America: Food Animal Practice, v.15, n.2, p.397-408, 1999.

FECTEAU, G. Management of peritonitis in cattle. Veterinary Clinics of North America: Food Animal Practice, v.21, p.155-171, 2005.

FRAME, N.W. Unusual tramatic reticuloperitonitis in a cow. The Veterinary Record, v.154, n.12, p.379, 2004.

HARWOOD, D. Alimentary tract perforation in cattle caused by tyre wire. The Veterinary Record, v. 154, n.18, p.574-575, 2004.

MARTINS, A.M.C.R.P.F.; LEME, M.C.M.; PORTUGAL, M.A.S.C.; BALDASSI, L.; MARGATHO, L.F.F. Presença de corpos estranhos no aparelho digestório dos bovinos. Arquivos do Instituto Biológico, São Paulo, v.71, n.1, p.8387, 2004

NUSS, K.; SCHWEIZER, G.; GERSPACH, C.; BRAUN, U. Hauben- und Labmagenfremdkörper bei einer Kuh - Diagnostik und Therapie. Ein Fallbericht. Tierärztliche Praxis, v.32 (G), p.122-125, 2004.

RAMPRABHU, R.; DHANAPALAN, P.; PRATHABAN, S. Comparative efficacy of diagnostic tests in the diagnosis of traumatic reticuloperitonitis and allied syndromes in cattle. Israel Journal of Veterinary Medicine, v.58, n.2/3, (não paginado), 2003

ROSENBERGER, G. Ungewöhnlich reichhaltige Fremdkörper-Ausbeute im Netzmagen einer Kuh. Deutsche tierärztliche Wochenschrift, v.77, p.155, 1970.

ROSENBERGER, G. Die klinische Untersuchung des Rindes. 3.ed. Berlin e Hamburg: Verlag Paul Parey, 1990. 718p.

ROTH, L.; KING, J.M. Traumatic reticulitis in cattle: a review of 60 fatal cases. Journal of Veterinary Diagnostic Investigation, v.3, p.52-54, 1991.

THORNTON, H. Foreign bodies in the organs of slaughtered animals. The Veterinary Record, v.95, p.342-343, 1974.

WARD, J.L.; DUCHARME, N.G. Traumatic reticuloperitonitis in dairy cows. Journal of the American Veterinary Medical Association, v.204, n.6, p.874-877, 1994.

WITTWER, F. Erfahrungen mit dem Käfigmagneten in der Fremdkörpertherapie. Schweizer Archiv für Tierheilkunde, v.102, p.621-624, 1966.

Rebido em 12/4/11

Aceito em 17/5/12 